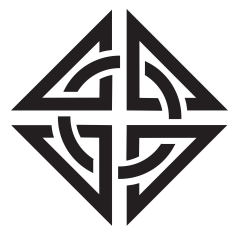

SCIENTIA

I RA N I C A
Sharif University of Technology

Scientia Iranica

Transactions C: Chemistry and Chemical Engineering

http://scientiairanica.sharif.edu

\title{
The effect of amine functionalized carbon nanotubes as promising support for platinum nanoparticles on oxygen reduction reaction
}

\author{
A. Yadegari ${ }^{a}$, A. Nouralishahi ${ }^{a, b, *}$, Y. Mortazavi ${ }^{a, *}$, A.A. Khodadadia \\ and A. Rashidic \\ a. Catalysis and Nanostructured Materials Research Laboratory, School of Chemical Engineering, University of Tehran, Tehran, \\ P.O. Box $11155 / 4563$, Iran. \\ b. Energy, Environment, and Nanostructured Materials Research Lab., Caspian Faculty of Engineering, University of Tehran, \\ Rezvanshahr, P.O. Box 43841-119, Iran. \\ c. Research Institute of Petroleum Industry (RIPI), Azadi Sport Complex West Blvd., Tehran, Iran.
}

Received 17 July 2017; received in revised form 22 April 2018; accepted 20 October 2018

\section{KEYWORDS \\ Amine functional groups; \\ Electrocatalysts; \\ Carbon nanotubes; \\ Oxygen reduction \\ reaction; \\ Pt nanoparticles.}

\begin{abstract}
In this study, multi-wall carbon nanotubes (MWCNTs) are chemically oxidized (OMWCNTs) and functionalized with ethylenediamine (EDAMWCNTs) and diethylenetriamine (DETAMWCNTs) as amine precursors. The electrocatalysts were prepared through deposition of $\mathrm{Pt}$ nanoparticles on the functionalized MWCNTs by polyol method. The average size of Pt nanoparticles was found to be between 4 and $5 \mathrm{~nm}$. Cyclic Voltammetry (CV), Rotating Disk Electrode (RDE), Electrochemical Impedance Spectroscopy (EIS), and Chronoamperometry (CA) were employed to evaluate the electrochemical properties of the electrocatalysts. The Electrochemical Active Surface Area (EASA), number of electrons transferred $(n)$, and onset potential of EDAMWCNTs and DETAMWCNTs were found to be about 32.2 and $45.8\left(\mathrm{~m}^{2} / \mathrm{g} \mathrm{Pt}\right), 4.03$ and 4.10 (electron per oxygen molecule), and 0.986 and 0.997 (V vs. RHE), respectively. However, in the case of Pt-OMWCNTs, the above-mentioned electrochemical characteristics were calculated to be $24.2\left(\mathrm{~m}^{2} / \mathrm{g} \mathrm{Pt}\right), 3.34$ (electron per oxygen molecule), and 0.824 (V vs. RHE), respectively. Moreover, EIS and CA indicate that introducing amine functional groups leads to low electron transfer resistance and better electrocatalytic activity and stability during oxygen reduction. The results show that the more the number of nitrogen atoms within the amine functional groups is, the more enhanced the electrocatalytic performance of Pt nanoparticles in ORR will be.

(C) 2018 Sharif University of Technology. All rights reserved.
\end{abstract}

\section{Introduction}

The augmentation of energy demand has led researchers to develop a novel, high-performance, and

*. Corresponding authors. Tel.: +982161113066

E-mail addresses: Nouralishahi@ut.ac.ir (A. Nouralishahi); Mortazav@ut.ac.ir (Y. Mortazavi)

doi: $10.24200 /$ sci. 2018.20916 economical energy resource instead of using fossil fuels [1-3]. The rate of current consumption of energy and environmental restrictions, chiefly emerging from the emission of greenhouse gases, is alarming [2,4]. Over the last five decades, renewable energy has attracted enormous attention due to its appropriate performance and environmentally-friendly energy storage and conversion [3]. Amongst all renewable energy sources and systems, solar cells [5], supercapacitors [6-8], and fuel cells [1] have been extremely examined recently. How- 
ever, the limitation of platinum-based catalysts [9] and the sluggish rate of the Oxygen Reduction Reaction (ORR) [10] have restricted the development of fuel cells on an industrial scale. Therefore, decreasing the platinum loading on support, enhancing the nanoparticles distribution, and optimizing the nanoparticles size are the most prominent factors in overcoming the aforementioned restrictions [11]. Up to now, carbon black has been utilized as a platinum-support commercial electro catalyst; however, it is not satisfactory at all chiefly due to its feeble interaction with platinum nanoparticles [12,13]. Hence, numerous studies have been performed on the decline of the platinum loading by utilizing carbon nanostructures as a promising support for fuel cells catalysis in order to reduce both the cost and kinetics of ORR [14]. Owing to the outstanding characteristics of carbon nanostructures such as their high stability in alkaline and acidic media [15], proper electron conductivity [16], and high specific surface area [17], they have demonstrated a pivotal role in utilizing electrocatalyst support for ORR in fuel cells. Carbon nanotubes are one-dimensional carbon nanostructures that have been widely utilized as an encouraging catalytic support for ORR [18]. In spite of the fact that carbon nanotubes are suitable electrocatalyst support, having an inactive surface has made the pristine carbon nanotubes contestable to reach the best $\mathrm{Pt}$ nanoparticles distribution [19-21]. Thus, altering the surface properties or modifying carbon nanotubes should be considered to increase its electrocatalytic activity [22]. Due to the enhancement of the electron donation by juxtaposing heteroatoms, such as nitrogen, on the neighboring of carbon atoms, functionalization and doping of carbon nanotubes with heteroatoms has been vastly inspected as a metalfree catalyst and promising supports for ORR [23-28]. Even though the synthesis of doped carbon nanotubes has enhanced the catalytic performance, sophisticated techniques, high-temperature conditions, product purification to remove residual metals, and ambiguity of improved ORR activity have partially overshadowed the utilization of heteroatom-doped carbon nanotubes [22]. In addition, functionalization of carbon nanotubes with amine and amide groups has been widely proposed to enhance the platinum nanoparticles distribution and ORR kinetics [10,15,29-32]. In the present study, ethylenediamine (EDA) and diethylenetriamine (DETA) are utilized as amine precursors to chemically functionalize the surface of multi-wall carbon nanotubes. For better demonstration of the critical impact of amine functional groups, the same strategy is applied to synthesize oxygen molecules containing functional carbon nanotubes, denoted as OMWCNTs. It is worth noting that nitrogen containing functional groups can be supplied as active sites for more effective nucleation and growth of platinum nanoparticles on the surface of MWCNTs. Additionally, the adsorption of oxygen molecules' active sites can be promoted due to superior accessibility of platinum nanoparticles.

\section{Experimental}

\subsection{Materials}

All the chemicals were used as they were received without any further treatment. Ethylenediamine, diethylenetriamine, sulfuric acid (98\%), nitric acid (70\%), hydrochloric acid (37\%), N,Ndimethylformamide (99.8\%), thionyl chloride (99\%), tetrahydrofuran, and ethanol were purchased from Merck. Nafion (5.0 wt\% solution) and hexachloroplatinic acid $\left(\mathrm{H}_{2} \mathrm{PtCl}_{6} \cdot 6 \mathrm{H}_{2} \mathrm{O} 37.0 \%\right)$ were purchased from Sigma Aldrich.

\subsubsection{Synthesis and purification of multi-wall carbon nanotubes}

The multi-wall carbon nanotubes were synthesized by chemical vapor deposition of $20 \%$ methane in hydrogen in the presence of $\mathrm{Co}-\mathrm{Mo} / \mathrm{MgO}$ as a catalyst at $800-$ $1000^{\circ} \mathrm{C}$ [33]. Purification of multi-wall carbon nanotubes was carried out to remove the metallic particles. Briefly, synthesized MWCNTs were refluxed in $2 \mathrm{M}$ $\mathrm{HCl}$ solution at $70^{\circ} \mathrm{C}$ for $6 \mathrm{~h}$. Subsequently, it was thoroughly washed with deionized water to reach the neutral $\mathrm{pH}$ and, then, was heated up to $250^{\circ} \mathrm{C}$ for $1 \mathrm{~h}$.

\subsection{Oxidation of $M W C N T s$}

The graphitic surface of MWCNTs was oxidized by putting multi-wall carbon nanotubes into a three-neck flask containing concentrated $\mathrm{H}_{2} \mathrm{SO}_{4}$ and $\mathrm{HNO}_{3}$ (3:1 $\mathrm{V} / \mathrm{V}$ ) at $70^{\circ} \mathrm{C}$ for $5 \mathrm{~h}$. The main purpose of the oxidation of MWCNTs is based on the comparison of oxygen containing functional groups such as hydroxyl and carboxyl, which can be obtained in this stage, and amine functional group, which is described in the following section.

\subsection{Amine-functionalization of MWCNTs}

Amine-functionalization of OMWCNTs was carried out by two different amine precursors to investigate the effect of adding the nitrogen atoms concentration by replacing diethylenetriamine instead of ethylenediamine. Briefly, $1.0 \mathrm{~g}$ of OMWCNTs was ultrasonically dispersed in a solution of thionyl chloride $\left(\mathrm{SOCl}_{2}\right)$ and dimethylformamide (DMF) (25:1). The black suspension was vigorously stirred at $70^{\circ} \mathrm{C}$ for $24 \mathrm{~h}$ under nitrogen atmosphere. The resulted sample was filtered and washed with an ample amount of tetrahydrofuran (THF) and, then, placed in a vacuum oven at $50^{\circ} \mathrm{C}$ for $8 \mathrm{~h}$. Afterwards, in order to attach amine functional groups on the surface of carbon nanotubes, $500 \mathrm{mg}$ of the OMWCNTs was mixed with $2.5 \mathrm{~g}$ of ethylenediamine or diethylenetriamine and sonicated in an ultrasonic bath for $2 \mathrm{~h}$. The amination reaction 


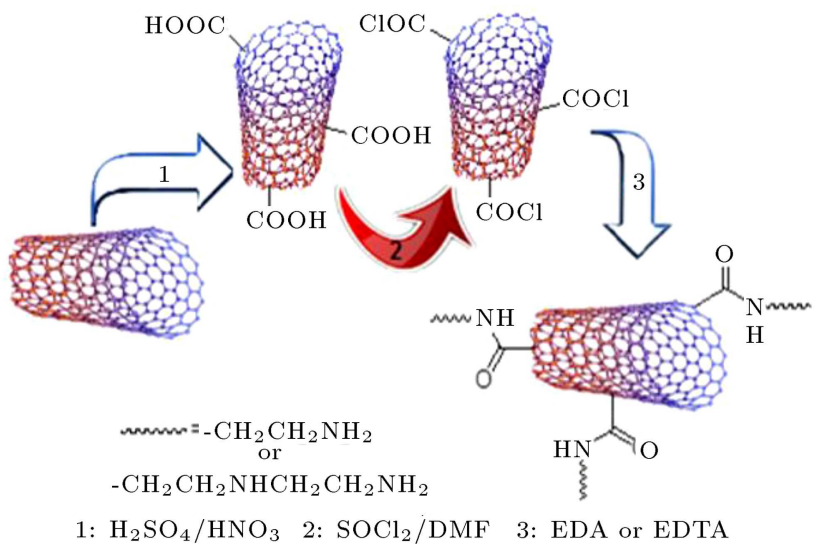

Figure 1. Schematic illustration of OMWCNTs functionalization with EDA or DETA.

occurred then in a deaerated medium under a reflux condition for $48 \mathrm{~h}$. The sample was washed with copious amount of pure ethanol and, then, was filtered. Finally, the amine-functionalized OMWCNTs, denoted as EDAMWCNTs and DETAMWCNTs, were dried at $65^{\circ} \mathrm{C}$ under a vacuum condition overnight. From now on, OMWCNTs, EDAMWCNTs, and DETAMWCNTs are denoted as FMWCNTs. The schematic synthesis procedure is illustrated in Figure 1.

\subsection{Preparation of Pt-FMWCNTs}

Pt nanoparticles were precipitated on the functionalized MWCNTs, i.e., FMWCNTs, through a polyol process using ethanol as the reducing agent. At the beginning, $0.2 \mathrm{~g}$ of treated carbon nanotubes was ultrasonically dispersed in $1 \mathrm{~L}$ of ethanol for $1 \mathrm{~h}$. Then, $100 \mathrm{cc}$ of hexachloroplatinic acid $\left(\mathrm{H}_{2} \quad \mathrm{PtCl}_{6} \cdot 6 \mathrm{H}_{2} \mathrm{O}\right)$ solution in ethanol was added drop-wise into the above suspension under vigorous stirring. The suspension was agitated in an ultrasonic bath for another $1 \mathrm{~h}$. The mixture was then deaerated by argon, and the reduction reaction was conducted under a reflux condition at $85^{\circ} \mathrm{C}$ for $18 \mathrm{~h}$. The resulted electro catalyst was washed with an ample amount of deionized water to remove chlorine ions and, then, dried in a vacuum oven at $70^{\circ} \mathrm{C}$ for $12 \mathrm{~h}$.

\subsection{Preparation of electrocatalysts and electrochemical measurements}

An ink-type electrocatalyst resulted from the synthesized Pt-FMWCNTs electrocatalysts. Then, $5 \mathrm{mg}$ of each electrocatalyst was ultrasonically dispersed for 30 minutes in a mixture of solvents containing $950 \mu \mathrm{l}$ of ethanol and deionized water $(1: 1 \mathrm{~V} / \mathrm{V})$ and $50 \mu \mathrm{l}$ of 1.0 wt\% nafion solution. A rotating Glassy Carbon Electrode (GCE) with the diameter of $3 \mathrm{~mm}$ was used to load the as-prepared ink. Prior to loading the electrocatalysts onto the glassy carbon electrode, it was carefully polished on a micro cloth with 0.05 and $0.3 \mu \mathrm{m}$ alumina slurry and, then, was washed with deionized water and ethanol, respectively, to remove any pollutant. Then, the GCE was further cleaned ultrasonically by immersing it into double distilled water to remove any remaining alumina particles. Subsequently, $5 \mu$ l of each electrocatalyst ink was loaded on the surface of GCE under irradiation of infrared lamp. Afterwards, the loaded GCE was held in an oven at $60^{\circ} \mathrm{C}$ for 10 minutes to cure the nafion polymer. Electrochemical measurements were conducted with a conventional three-electrode cell in a $0.5 \mathrm{M} \mathrm{H}_{2} \mathrm{SO}_{4}$ solution as an electrolyte at room temperature. As mentioned earlier, a rotating GCE was used as the working electrode; $\mathrm{Ag} / \mathrm{AgCl}$ and $\mathrm{Pt}$ wire were used as the reference and counter electrodes, respectively. All the electrochemical data were recorded using an Autolab potentiostat/galvanostat (PGSTAT30 Eco Chemie, B.V, The Netherlands) instrument along with Rotating Disk Electrode (RDE) system. Prior to conducting the electrochemical experiments, including Cyclic Voltammetry (CV), Linear Sweep Voltammetry (LSV), chronoamperometry, and Electrochemical Impedance Spectroscopy (EIS), $25 \mathrm{ml}$ of $0.5 \mathrm{M} \mathrm{H}_{2} \mathrm{SO}_{4}$ was properly purged with pure oxygen for 30 minutes to remove other soluble gases, if any. All the measured potentials in this study are based on the Reversible Hydrogen Electrode (RHE).

\subsection{Physical characterization instruments}

The X-ray powder diffraction was performed on PW 1840 Philips diffractometer using $\mathrm{Cu} \operatorname{K} \alpha 1 \quad(\lambda=$ $1.54056 \AA$ ) to examine crystalline structure of the electrocatalysts. The diffraction patterns were recorded in the $2 \theta$ extent from 15 to $90^{\circ}$ with a scan rate of $1.2^{\circ}$ $(2 \theta) / \mathrm{min}$. X-ray photoelectron spectroscopy (XPS, Bestec instruments, ultra-spectrometer $\mathrm{Mg} \mathrm{K \alpha}$ and monochromatic Al K $\alpha$ source operating) was also done to evaluate the electronic structure of carbon, nitrogen, and oxygen atoms on the surface of electrocatalysts. The operating pressure and base pressure were set to about $2 \times 10^{-10}$ and $1 \times 10^{-10}$ torr, respectively. A wide scan survey at high-resolution spectra was also conducted to evaluate the accuracy of FMWCNTs. Moreover, Fourier transition infrared (Perkin Elmer FTIR Analyzer) was used to further investigate the attachment of functional groups to MWCNTs. The distribution of platinum nanoparticles and the morphology of the electrocatalysts were characterized by transmission electron microscopy (TEM, ZEISS 900).

\section{Results and discussion}

\subsection{Physicochemical characterization}

Figure 2 depicts the XRD patterns of the electrocatalysts. The diffraction peaks in the vicinity of 25,43 , 55 , and $76^{\circ}(2 \theta)$ can be attributed to the graphitic structure and hexagonal crystallinity of carbon atoms 


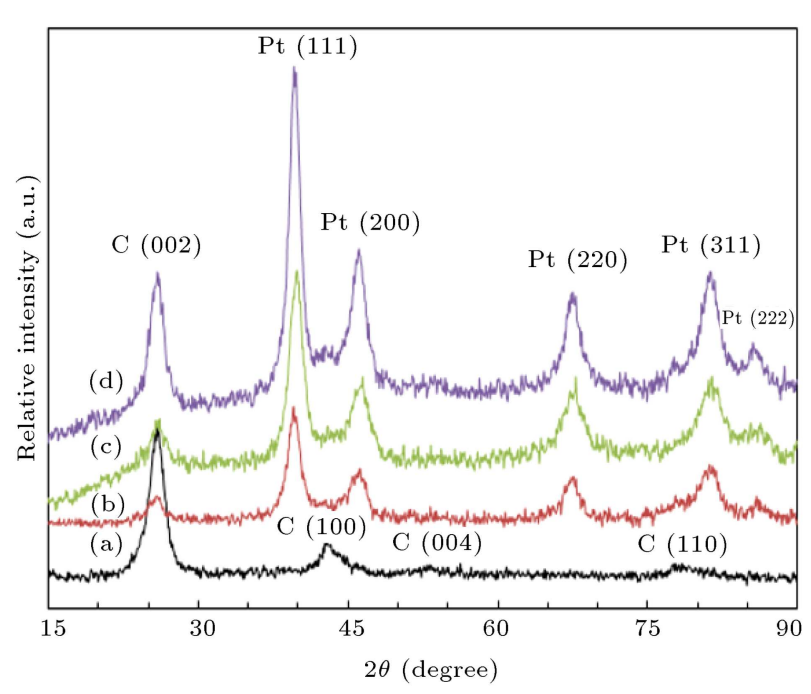

Figure 2. XRD patterns of electrocatalysts: (a) MWCNTs, (b) Pt-OMWCNTs, (c) Pt-EDAMWCNTs, and (d) Pt-DETAMWCNTs.

on (002), (100), (004), and (110) planes of OMWCNTs, respectively [34,35]. The diffraction peaks at 39,45 , 67,80 , and $85(2 \theta)$ degrees in spectra (b), (c), and (d) in Figure 2 may be ascribed to the crystallinity of Pt nanoparticles on (111), (200), (220), (311), and (222) planes, respectively [36]. As a result, the XRD patterns confirm the deposition of $\mathrm{Pt}$ nanoparticles as a face-centered-cubic structure on the functionalized carbon nanotubes. The average size of $\mathrm{Pt}$ nanoparticles was estimated by Scherrer equation, regarding (200) or (111) plane of Pt crystals, showing the largest intensity among other Pt planes $[37,38]$ :

$$
d=\frac{0.9 \lambda}{B \cos 2 \theta} \text {. }
$$

In this equation, $d$ stands for the average size of $\mathrm{Pt}$ nanoparticles $(\mathrm{nm}), \lambda$ is related to the $\mathrm{X}$-ray wavelength which is $1.5406 \AA$ for $\mathrm{Cu} \mathrm{K} \alpha$ radiation, $B_{2 \theta}$ is regarded as the width of the diffraction peak at half maximum height, and $\theta$ is defined as the angle corresponding to the maximum peak (degree). Considering the Scherrer equation, the average sizes of platinum nanoparticles on functionalized multi-wall carbon nanotubes were calculated to be about 4.8, 4.0, and $3.2 \mathrm{~nm}$ for OMWCNTs, EDAMWCNTs, and DETAMWCNTs, respectively. These sizes are reasonably confirmed by TEM images, which are presented later on. The size of $\mathrm{Pt}$ calculated from the XRD patterns indicates that platinum dispersed on the surface of the amine-functionalized CNTs has smaller sizes. Due to the fact that amine functional groups provide basic sites on the surface of carbon nanotubes, the presence of EDA and DETA functional groups not only improves the nucleation and growth of $\mathrm{Pt}$ nanoparticles on the surface of modified carbon nanotubes, but also accelerates the precipitation process $[34,39,40]$.
TEM images of the pristine multi-wall carbon nanotubes and electrocatalysts are shown in Figure 3. The image of the as-synthesized multi-wall carbon nanotubes (Figure 3(a)) clearly indicates the presence of carbonaceous and residual metal impurities in particles. As Figure 3(b) shows, these impurities were obviously removed by refluxing the multi-wall carbon nanotubes in $2 \mathrm{M}$ HCL solution. After the oxidation process, there are more individual nanotubes along with more open or broken tubes that could be attributed to the functionalization of carbon nanotubes.

The images of samples: Pt-OMWCNTs, PtEDAMWCNTs, and Pt-DETAMWCNTs reveal that platinum nanoparticles have been successfully deposited on the surface of the functionalized carbon nanotubes without any noticeable agglomeration; however, the size distribution of $\mathrm{Pt}$ nanoparticles ranges from 1 to about $8 \mathrm{~nm}$ in each case. According to these images, the deposition and distribution of $\mathrm{Pt}$ nanoparticles can be changed when the amine-functionalized carbon nanotubes have been utilized as the support instead of OMWCNTs. In the case of Pt-EDAMWCNTs, the presence of two amine groups can play an important role in enhancing the nucleation sites on the support due to the creation of more basic sites for anchoring $\mathrm{Pt}$ nanoparticles in comparison with Pt-OMWCNTs electro catalyst. Moreover, regarding Figure 3(d), the dispersion of $\mathrm{Pt}$ nanoparticles has improved even more owing to the presence of one more nitrogen atom in the case of DETAMWCNTs, which could act as a favorable site for better distribution of $\mathrm{Pt}$ nanoparticles on the surface of carbon nanotubes.

The functionalization of carbon nanotubes with oxygen- or amine-containing groups was confirmed by FTIR spectra, as presented in Figure 4. The weak peak near $680 \mathrm{~cm}^{-1}$ for all the samples can be related to $\mathrm{C}$ $\mathrm{H}$ aromatic bending vibrations due to the formation of $\mathrm{C}-\mathrm{H}$ bonds on the defective structure of carbon nanotubes and acidic hydrogen in the oxidized sample. In addition, two weak peaks at 1374 and $1443 \mathrm{~cm}^{-1}$ could be ascribed to the backbone structures of multiwall carbon nanotubes present in all the spectra. The FTIR spectrum of OMWCNTs is shown in Figure 4(a). The distinctive peaks at $1212,1536,1698,2947$, and $3479 \mathrm{~cm}^{-1}$ are attributed to $\mathrm{C}-\mathrm{O}, \mathrm{C}=\mathrm{C}, \mathrm{C}=\mathrm{O}, \mathrm{C}-$ $\mathrm{H}$, and $\mathrm{O}-\mathrm{H}$ bonds, respectively [41-43]. As it can be observed in Figure 4(b) and (c), the emerging distinctive peaks in the vicinity of 1096 and $1088 \mathrm{~cm}^{-1}$ are regarded as the $\mathrm{C}-\mathrm{N}$ stretching band in the spectra of EDAMWCNTs and DETAMWCNTs, respectively $[44,45]$. Accordingly, the wave numbers of C-O, $\mathrm{C}=\mathrm{C}, \mathrm{C}=\mathrm{O}$, and $\mathrm{O}-\mathrm{H}$ peaks of EDAMWCNTs and DETAMWCNTs have been shifted as compared with those of OMWCNTs due to the formation of amine functional groups on the carbon nanotubes. Moreover, two peaks at 1680 and $1688 \mathrm{~cm}-1$ are attributed to the 


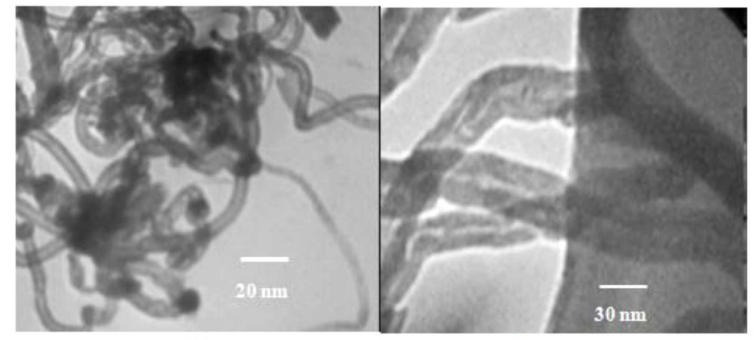

(a)

(b)

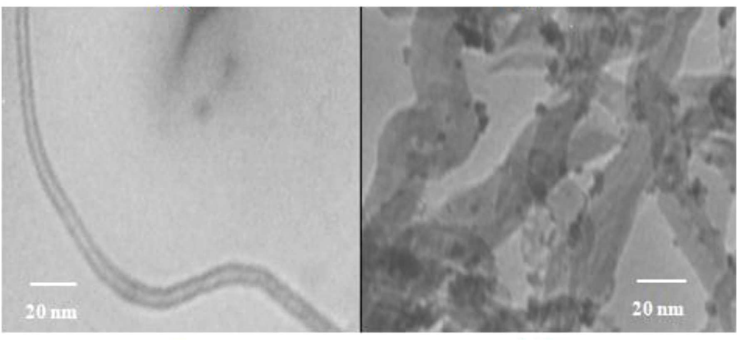

(c)

(d)

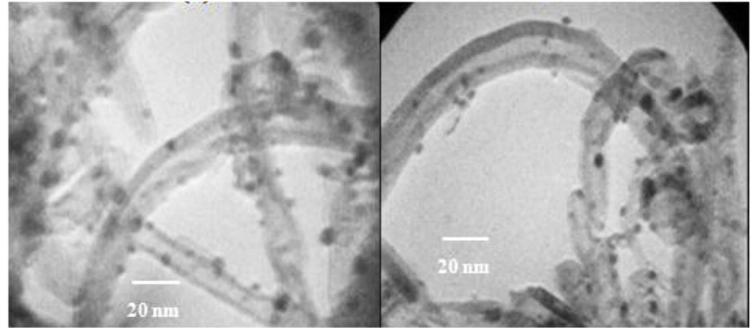

(e)

(f)

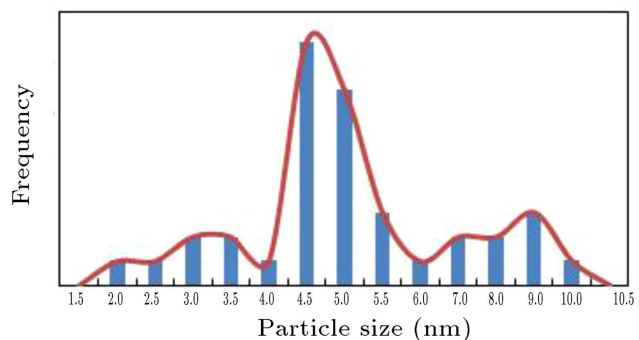

(g)

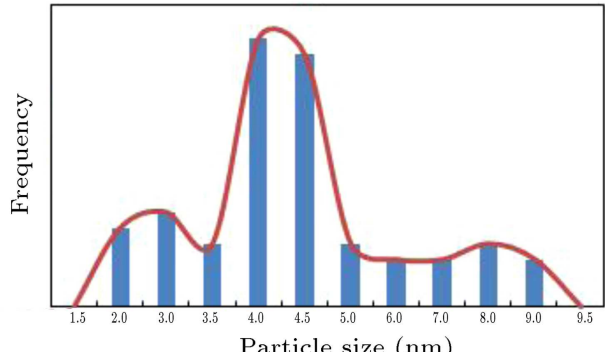

(h)

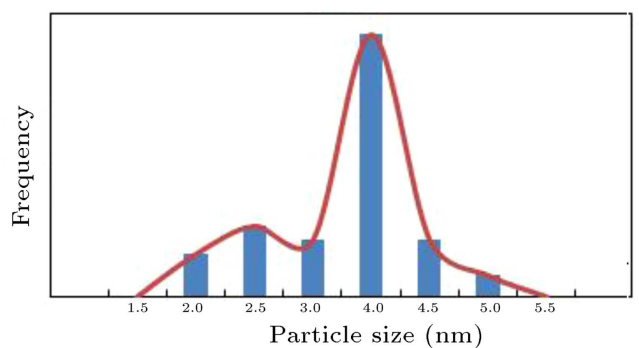

(i)

Figure 3. TEM images of electrocatalysts including (a) unpurified MWCNTs, (b) purified MWCNTs with 2M HCl, (c) oxidized MWCNTs with $\mathrm{H}_{2} \mathrm{SO}_{4}$ and $\mathrm{HNO}_{3}(3: 1 \mathrm{~V}: \mathrm{V})$, (d) Pt-OMWCNTs, (e) Pt-EDAMWCNTs, (f) Pt-DETAMWCNTs. Particle size distribution of (g) Pt-OMWCNTs, (h) Pt-EDAMWCNTs, and (i) DETAMWCNTs.

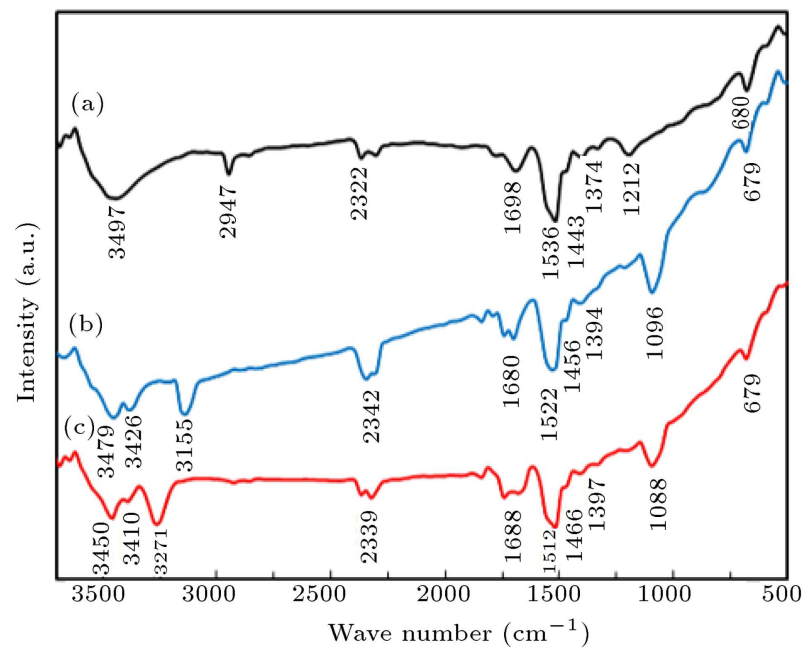

Figure 4. FT-IR spectra of (a) oxidized MWCNTs, (b) EDAMWCNTs, and (c) DETAMWCNTs.

$\mathrm{N}-\mathrm{H}$ bending for EDAMWCNTs and DETAMWCNTs, respectively [45]. The peaks at 3155 and $3271 \mathrm{~cm}^{-1}$ are assigned to the $\mathrm{C}-\mathrm{H}$ bond stretching of the EDA and DETA precursors [45]. Additionally, the presence of two twin peaks at 3426 and $3479 \mathrm{~cm}^{-1}$ for EDAMWCNTs and 3410 and $3450 \mathrm{~cm}^{-1}$ for DETAMWCNTs is related to $\mathrm{N}-\mathrm{H}_{2}$ bond stretching as a symmetric or asymmetric mode [46]. Hence, the formation of amine functional groups on the surface of OMWCNTs could be verified according to the FTIR spectra.

In addition to FTIR spectra, X-ray photoelectron spectroscopy was further conducted to investigate the formation of functional groups on the surface of MWCNTs. The XPS survey spectra of the pristine multi-wall carbon nanotubes, i.e., OMWCNTs, EDAMWCNTs, and DETAMWCNTs, are shown in Figure 5(a). The strong peaks in the vicinity of $284 \mathrm{eV}$ can be clearly observed in the wide spectra of all the samples relating to $\mathrm{sp}^{2}$ hybridized carbon nanotubes [47]. As it is observed in this figure, there is no other obvious peak in the spectrum of the pristine carbon nanotubes, while, in the spectrum of OMWCNTs, the appearance of O1s peak at around $532 \mathrm{eV}$ is noticeable [48]. Moreover, the presence of distinctive peaks at $400 \mathrm{eV}$ in the XPS spectra of EDAMWCNTs and DETAMWCNTs can be assigned to N1s peaks, whereas there are no peaks in this region in the spectrum of OMWCNTs and 


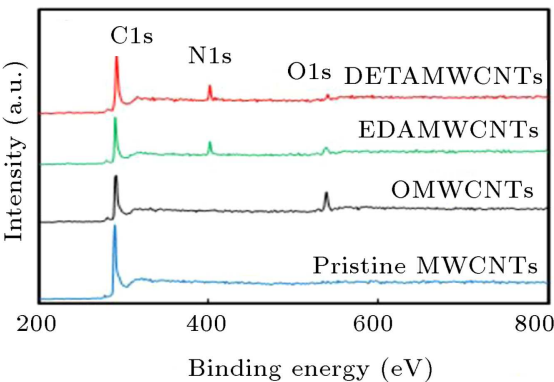

(a)

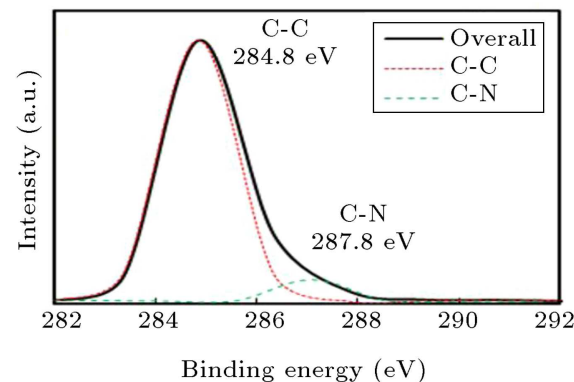

(c)

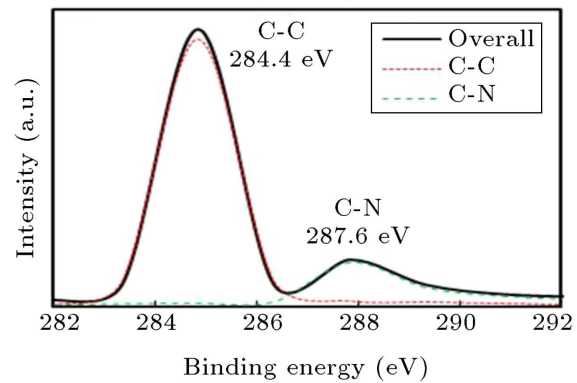

(e)

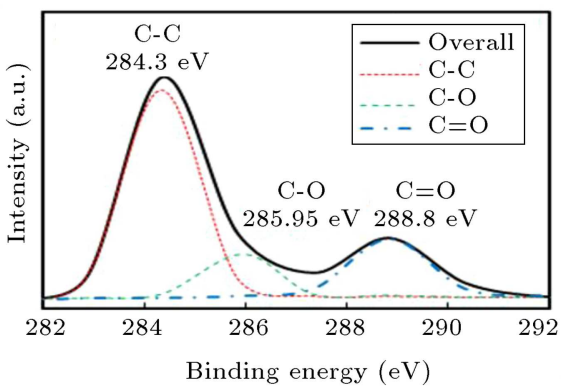

(b)

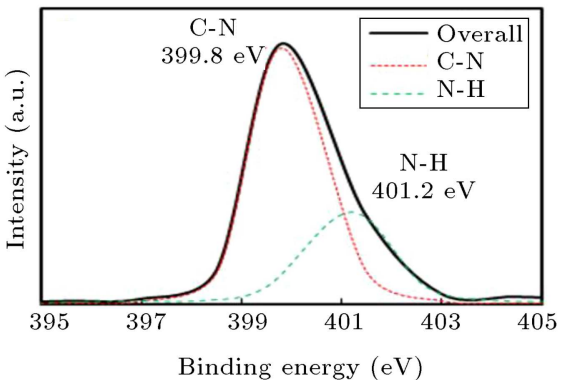

(d)

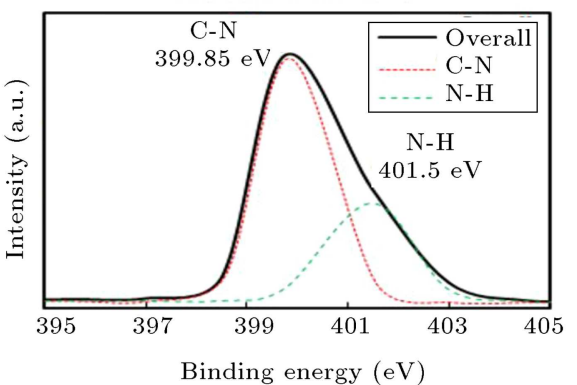

(f)

Figure 5. X-ray photoelectron spectra of (a) a wide scan of pristine, OMWCNTs, EDAMWCNTs, and DETAMWCNTs; and high-resolution spectra of (b) OMWCNTs C1s, (c) EDAMWCNTs C1s, (d) EDAMWCNTs N1s, (e) DETAMWCNTs C1s, and (f) EDAMWCNTs N1s.

the pristine carbon nanotubes indicating the formation of amine functional groups [13,49]. High-resolution XPS spectra of $\mathrm{C} 1 \mathrm{~s}$ for OMWCNTs are shown in Figure 5(b). The C1s spectra of OMWCNTs are divided into three major components at 284.3, 285.9, and $288.8 \mathrm{eV}$ that are attributed to $\mathrm{C}-\mathrm{C}, \mathrm{C}-\mathrm{O}$, and $\mathrm{C}=\mathrm{O}$ bonds, respectively $[46,50]$. The high-resolution XPS spectra of $\mathrm{C} 1 \mathrm{~s}$ and N1s for EDAMWCNTs are depicted in Figure 5(c) and (d), respectively. The C1s peaks are composed of two main components at 284.8 and $287.8 \mathrm{eV}$ relating to $\mathrm{C}-\mathrm{C}$ and $\mathrm{C}-\mathrm{N}$ bonds, respectively [50]. Higher energy bonding at $287.8 \mathrm{eV}$ relating to $\mathrm{C}-\mathrm{N}$ bond in comparison with $\mathrm{C} 1 \mathrm{~s}$ main peaks of OMWCNTs indicates the formation of amine functional groups [51]. Furthermore, the elimination of a peak at around $288.8 \mathrm{eV}$ indicates the reduction of carboxylic functional groups to an amine functional group [52]. Since N1s energy bindings for amine functional groups are reported to be between 399.5 and $400.5 \mathrm{eV}[53,54]$, N1s peaks of EDAMWCNTs at
399.8 and $401.2 \mathrm{eV}$ correspond to C-N and N-H bonds, respectively [52]. The high-resolution XPS spectra of C1s and N1s for DETAMWCNTs are illustrated in Figure 5(e) and (f), respectively. The two distinctive $\mathrm{C} 1 \mathrm{~s}$ peaks at 284.4 and $287.6 \mathrm{eV}$ are attributed to $\mathrm{C}-\mathrm{C}$ and C-N bonds, respectively [49]. Compared with EDAMWCNTs, the C1s peak at $287.6 \mathrm{eV}$ shows a stronger peak that might be associated with the formation of more amine functional groups in the case of diethylenetriamine functionalization or greater reduction of carboxylic acid in amine functional groups. N1s peaks of DETAMWCNTs show two main energy bindings at 399.8 and $401.5 \mathrm{eV}$, which are assigned to C-N and N-H bonds, respectively [49]. As predicted, the absence of N1s peaks in the pristine and OMWCNTs XPS spectra confirms the formation of amine functional groups through functionalization of oxidized multi-wall carbon nanotubes with ethylendiamiene and diethylenetriamine. Hence, the XPS results are quite consistent with the FTIR spectra; both techniques 
indicate the functionalization of carbon nanotubes with oxygen and nitrogen containing functional groups.

The atomic concentrations of carbon, nitrogen, and oxygen were estimated on the basis of XPS results, as summarized in Table 1 . The higher oxygen concentration of the OMWCNTs is due to the formation of carboxylic and hydroxyl functional groups, whereas lower oxygen content is indicative of amine functionalization of carbon nanotubes for EDAMWCNTs and DETAMWCNTs. Moreover, nitrogen atomic concentration rates of EDAMWCNTs and DETAMWCNTs were found to be about 5.3 and $8.7 \%$, respectively. Increasing the concentration of nitrogen atoms in DETAMCNTs may be ascribed to the amount of amine groups in DETA, which is more than that of EDA. Therefore, according to the XPS results, the formation of the larger amount of amine functional groups, which is favorable for oxygen reduction reaction, is more likely by using DETA as compared to EDA.

\subsection{Electrochemical characterization of the electrocatalysts}

\subsubsection{Cyclic voltammetry}

Figure 6 shows the cyclic voltammetry of the synthesized electrocatalysts in oxygen-saturated $\mathrm{H}_{2} \mathrm{SO}_{4}$ at $25^{\circ} \mathrm{C}$. At the beginning of each $\mathrm{CV}$ test, the surface of electrodes was cleaned by sweeping two or three cycles to remove possible residual impurities. The Electrochemical Active Surface Area (EASA) of the electrocatalysts was calculated according to adsorption and desorption charge associated with hydrogen on $\mathrm{Pt}$ crystals known as Hupd (under-potential deposition on $\mathrm{Pt}$ ) [55]. The EASA was estimated assuming 0.21 $\mathrm{mC} / \mathrm{cm}^{2} \mathrm{Pt}$, as is summarized in Table 2. According to Figure 6 and Table 2, the amount of EASA for Pt-DETAMWCNTs is higher than those of PtEDAMWCNTs and Pt-OMWCNTs, indicating better dispersion of $\mathrm{Pt}$ nanoparticles due to the presence of amine functional groups. The role of amine functional groups is accentuated by increasing the number of nitrogen atoms at DETAMWCNTs as compared to EDAMWCNTs. Therefore, higher EASA and more positive onset potential are ascribed to the role of amine functional groups as a prominent factor in improving the catalytic activity of $\mathrm{Pt}$ nanoparticles by better nucleation and growth, resulting in higher platinum dispersion [56].

\subsubsection{Rotating Disk Electrode measurement ( $R D E$ )}

Linear sweep voltammetry was conducted by rotating disk electrode at various rotational speeds in oxygensaturated $0.5 \mathrm{M} \mathrm{H}_{2} \mathrm{SO}_{4}$ at $25^{\circ} \mathrm{C}$. The polarization curves of the electrocatalysts are shown in Figure 7 at the rotational speed of $1500 \mathrm{rpm}$. The onset potential of Pt-DETAMWCNTs (0.997 V vs RHE) and PtEDAMWCNTs $(0.984 \mathrm{~V})$ is clearly higher than that of Pt-OMWCNTs $(0.824 \mathrm{~V})$ due to the presence of amine functional groups. Amine functional groups on

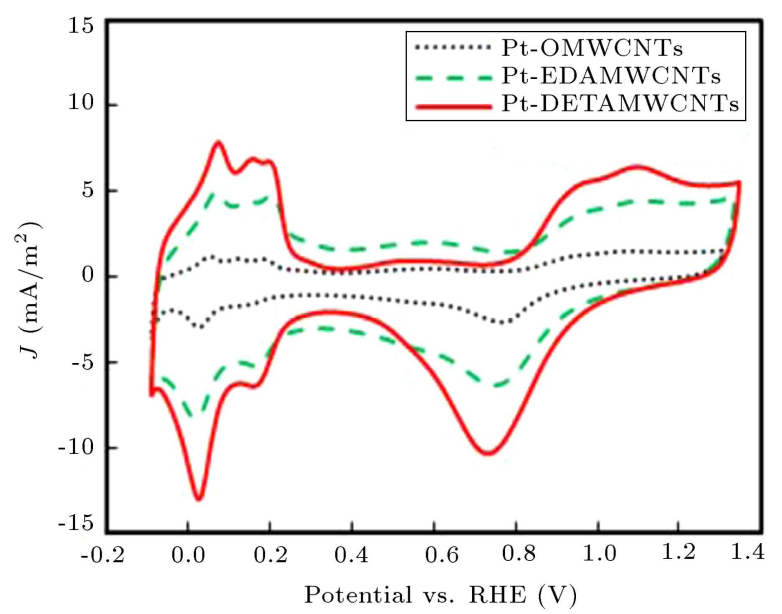

Figure 6. Cyclic voltammetry of Pt-OMWCNTs, Pt-EDTAMWCNTs, and Pt-DETAMWCNTs in $\mathrm{O}_{2}$ saturated $0.5 \mathrm{M} \mathrm{H}_{2} \mathrm{SO}_{4}$ aqueous solution at a scan rate of $50 \mathrm{mV} / \mathrm{s}$ and $25^{\circ} \mathrm{C}$.

Table 1. Calculated atomic concentration of functionalized carbon nanotubes from XPS.

\begin{tabular}{ccc}
\hline Sample & $\begin{array}{c}\text { Concentration of } \\
\text { nitrogen (atomic \%) }\end{array}$ & \begin{tabular}{c} 
Concentration of oxygen (atomic \%) \\
\hline OMWCNTs
\end{tabular} NA $_{\text {EDAMWCNTs }}$ \\
DETAMWCNTs & 5.3 & 15.4 \\
\hline
\end{tabular}

Table 2. The amount of EASA, onset potential, and number of transferred electrons for electrocatalysts.

\begin{tabular}{ccccc}
\hline Electrocatalyst & $\begin{array}{c}\text { Pt loading } \\
(\mathbf{w} \mathbf{t} \%)\end{array}$ & $\begin{array}{c}\text { EASA } \\
\left(\mathbf{m}^{\mathbf{2}} \mathbf{g}^{-\mathbf{1}} \mathbf{P t}\right)\end{array}$ & $\begin{array}{c}\text { Onset potential } \\
(\mathbf{V} \text { vs } \mathbf{R H E})\end{array}$ & $\begin{array}{c}\text { Number of Transferred } \\
\text { Electron }(\mathbf{n})\end{array}$ \\
\hline Pt-OMWCNTs & 10 & 24.2 & 0.824 & 3.34 \\
Pt-EDTAMWCNTs & 10 & 32.2 & 0.986 & 4.03 \\
Pt-DETAMWCNTs & 10 & 45.8 & 0.997 & 4.10 \\
\hline
\end{tabular}




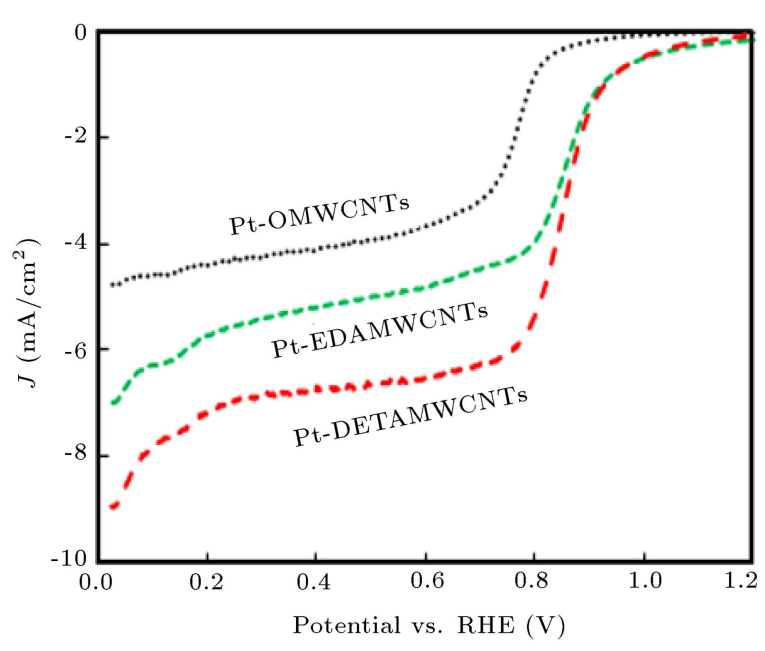

Figure 7. Polarization curves of Pt-OMWCNTs, Pt-EDTAMWCNTs, and Pt-DETAMWCNTs in $\mathrm{O}_{2}$ saturated $0.5 \mathrm{M} \mathrm{H}_{2} \mathrm{SO}_{4}$ aqueous solution at a scan rate of $5 \mathrm{mV} / \mathrm{S}$, rotation speed of $1500 \mathrm{rpm}$, and $25^{\circ} \mathrm{C}$.

the surface of carbon nanotubes lead to a uniform distribution of $\mathrm{Pt}$ nanoparticles [56,57]. Moreover, ORR activity is significantly influenced by the dispersion and coordination of platinum nanoparticles [5860]. Hence, the positive shift of onset potential for Pt-DETAMWCNTs and Pt-EDAMWCNTs may be ascribed to better accessibility of $\mathrm{Pt}$ nanoparticles for oxygen molecules due to the role of amine functional groups in improving the nucleation, growth, and dispersion of $\mathrm{Pt}$ nanoparticles. In addition, according to most of the proposed ORR mechanisms, the formation of oxygenated radicals and other oxygenated species intermediates, especially $\mathrm{OH}_{\text {ads }}$, during the ORR reaction leads to the decreasing or inhibition of the normal reduction of oxygen molecules [61]. The augmentation of intermediate species carries out ORR reaction toward the 2-electron pathway instead of the 4-electron pathway [62]. According to Figure 7, the polarization curves show that any probable formation of oxygenated species is decreased by introducing the amine functional groups. As is observed, this behavior is further supported by increasing the amount of cathodic current density due to the better electrocatalytic activity of $\mathrm{Pt}$ nanoparticles in the presence of amine functionalized carbon nanotubes.

The higher electrocatalytic activity of Pt- DETAMWCNTs in comparison with Pt-EDAMWCNTs and Pt-OMWCNTs can be also attributed to weaker chemical adsorption energy of the produced intermediate, i.e., hydroxyl species during oxygen reduction $[58,63]$. Of note, enhancing the electrocatalytic activity of $\mathrm{Pt}$ nanoparticles through decreasing the chemical adsorption energy of hydroxyl species firmly depends on the geometry and homogeneous dispersion of nanoparticles on the surface of supports [64]. Thus, the better the dispersion and coordination of $\mathrm{Pt}$ nanoparticles, the higher the electrocatalytic activity of $\mathrm{Pt}$ nanoparticles towards ORR. As can be seen in the polarization curves, the onset potential of the adsorbed hydroxyl species for Pt-DETAMWCNTs is much higher than those of Pt-EDAMWCNTs and Pt-OMWCNTs, demonstrating the more attenuation of the chemical adsorption energy by increasing the concentration of nitrogen atoms. This observation is supported by TEM images and XPS results that revealed better dispersion of $\mathrm{Pt}$ nanoparticles and higher content of nitrogen atoms for Pt-DETAMWCNTs sample. The kinetics behavior of the electrocatalysts was also investigated by increasing the rotational speed of the RDE electrode from 250 to $4500 \mathrm{rpm}$. Figure 8 presents the polarization curves and the corresponding Koutecky-Levich plots for all of the electrodes at various rotational speeds and potentials, respectively.

The number of electrons transferred was calculated by plotting the Koutecky-Levich equation, including a plot of inverse current density $(1 / J)$ versus the inverse of the square root of the rotational speed $\left(\omega^{-1 / 2}\right)$. The slope of this plot leads to calculating the number of electrons transferred in oxygen reduction reaction through the following equations.

$$
\frac{1}{J}=\frac{1}{J_{k}}+\frac{1}{B \omega^{0.5}}
$$

where $J\left(\mathrm{~mA} / \mathrm{cm}^{2}\right)$ is the measured current at linear sweep voltammetry, $J_{k}\left(\mathrm{~mA} / \mathrm{cm}^{2}\right)$ is the kinetic current, $\omega$ is the rotational speed (rpm), and $B$ is defined as the following equation:

$$
B=0.2 n F A D_{O_{2}}^{2 / 3} \nu^{-1 / 6} C_{O_{2}} \omega^{1 / 2},
$$

where $n$ is the number of transferred electrons, $F$ is the Faraday constant $(96500 \mathrm{C} / \mathrm{mol}), A$ is the surface area of the electrode, $\mathrm{D}_{\mathrm{O}_{2}}$ is the diffusion coefficient of oxygen in electrolyte $\left(1.61 \times 10^{-5} \mathrm{~cm}^{2} / \mathrm{s}\right), \nu$ is the kinematic viscosity of the electrolyte $\left(1.00 \times 10^{-2} \mathrm{~cm}^{2} / \mathrm{s}\right)$, and $\mathrm{CO}_{2}$ is the concentration of the dissolved oxygen in the electrolyte $\left(1.15 \times 10^{-6} \mathrm{~mol} / \mathrm{cm}^{3}\right)$ [65]. The number of electrons transferred was found to be $3.34,4.03$, and 4.10 for Pt-OMWNCTs, Pt-EDAMWCNTs, and Pt-DETAMWCNTs, respectively. Since the desirable pathway in ORR is the $4 \mathrm{e}^{-}$reduction pathway [66], the number of electrons transferred indicates that functionalization of carbon nanotubes with amine functional groups improves the catalytic efficiency of the Pt nanoparticles throughout the reduction of oxygen molecules by increasing the number of transferred electrons.

\subsubsection{Electrochemical Impedance Spectroscopy (EIS)}

Electrochemical impedance spectroscopy was performed to further investigate the electrochemical behavior of the electrocatalysts. Figure 9 shows the 


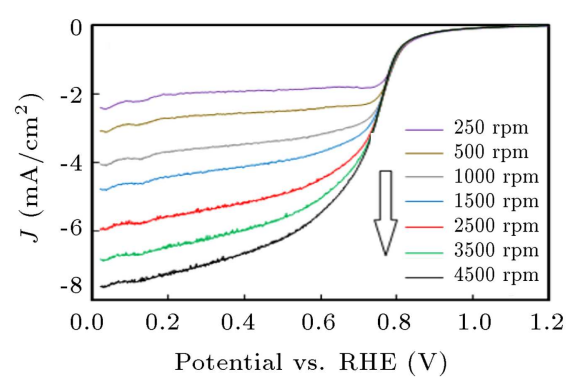

(a)

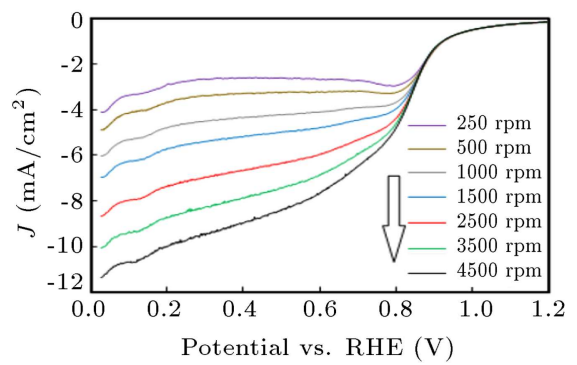

(c)

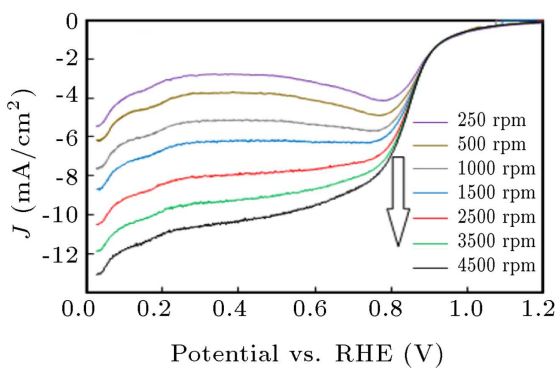

(e)

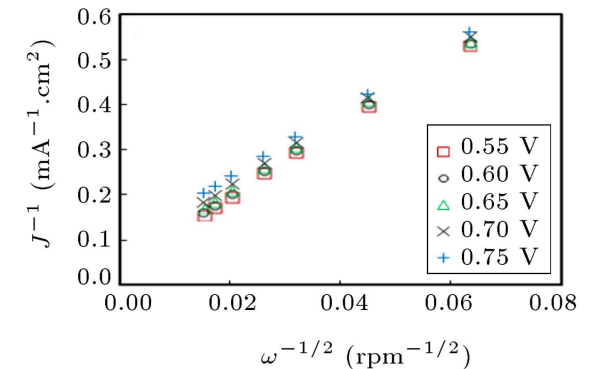

(b)

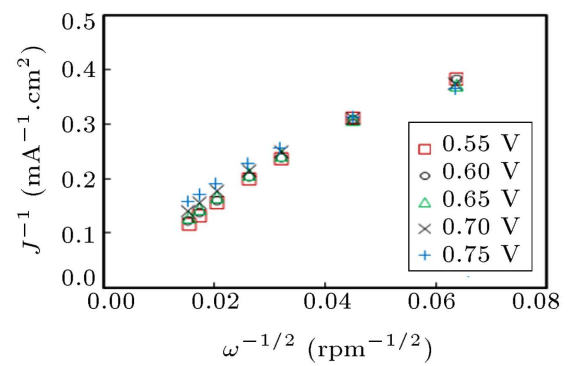

(d)

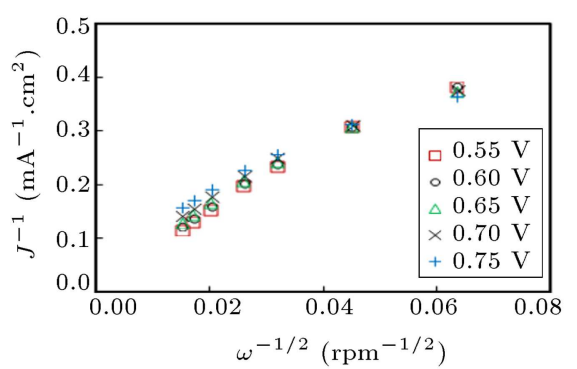

(f)

Figure 8. RDE measurements at various rotational speeds and corresponding Koutecky-Levich plots: (a \& b) Pt-OMWCNTs, (c \& d) Pt-EDAMWCNTs, and (e \& f) Pt-DETAMWCNTs. All data were gathered in oxygen-saturated $0.5 \mathrm{M} \mathrm{H}_{2} \mathrm{SO}_{4}$ at $25^{\circ} \mathrm{C}$ with a scan rate of $5 \mathrm{mV} / \mathrm{s}$.

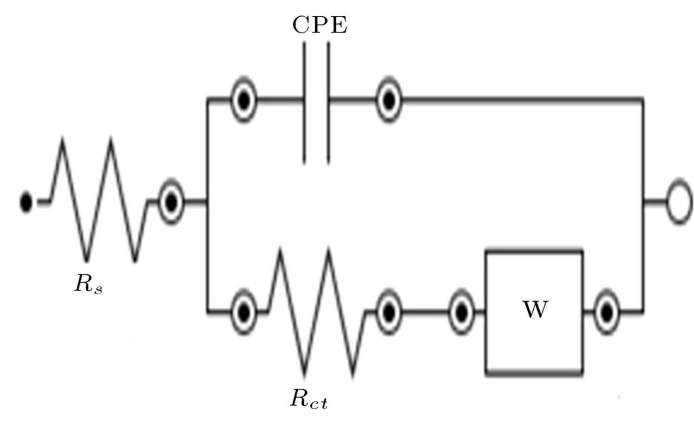

Figure 9. Equivalent circuit used for fitting EIS experimental data.

equivalent circuit for fitting experimental EIS data in which $R_{s}, R_{c t}$, CPE, and $\mathrm{W}$ stand for the solution ohmic resistance, charge transfer resistance, constant phase element used as double layer capacitance owing to inhomogeneous electrocatalysis surface, and Warburg impedance, respectively [67-69]. The equivalent circuit proposes that polarization is assigned to a combination of kinetics and diffusion processes [67]. Figure 10 shows that all of the experimental EIS

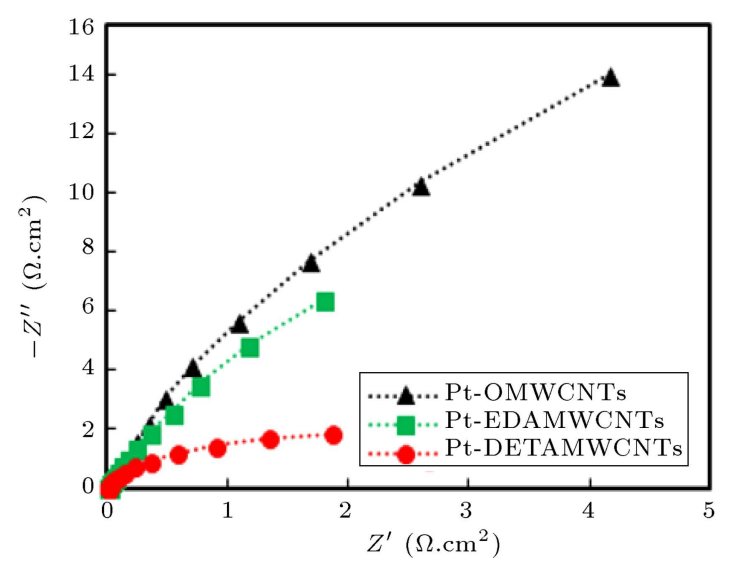

Figure 10. Impedance spectroscopy of the electrocatalysts at OCP potential $(0.65 \mathrm{~V}$ versus $\mathrm{Ag} / \mathrm{AgCl})$ in oxygen-saturated $0.5 \mathrm{M} \mathrm{H}_{2} \mathrm{SO}_{4}$ at $25^{\circ} \mathrm{C}$ with the frequency scan of 0.1 to $100000 \mathrm{~Hz}$.

results are conveniently fitted on the model EIS plots for Pt-OMWNCTs, Pt-EDAMWCNTs, and PtDETAMWCNTs at open-circuit potentials $(0.65 \mathrm{~V}$ vs $\mathrm{Ag} / \mathrm{AgCl}$ ). According to the Nyquist plots, the 
Table 3. Equivalent circuit parameters of the electrocatalysts.

\begin{tabular}{ccccc}
\hline Electrocatalyst & $\boldsymbol{R}_{\boldsymbol{s}}\left(\boldsymbol{\Omega} \cdot \mathbf{c m}^{\mathbf{2}}\right)$ & $\boldsymbol{R}_{\boldsymbol{c t}}\left(\boldsymbol{\Omega} \cdot \mathbf{c m}^{\mathbf{2}}\right)$ & $\mathbf{C P E}(\boldsymbol{\mu} \mathbf{F})$ & W $(\boldsymbol{\mu} \mathbf{M h o})$ \\
\hline Pt-OMWCNTs & 0.09 & 2.19 & 546 & 195 \\
Pt-EDAMWCNTs & 0.05 & 1.78 & 881 & 122 \\
Pt-DETAMWCNTs & 0.03 & 0.52 & 990 & 118 \\
\hline
\end{tabular}

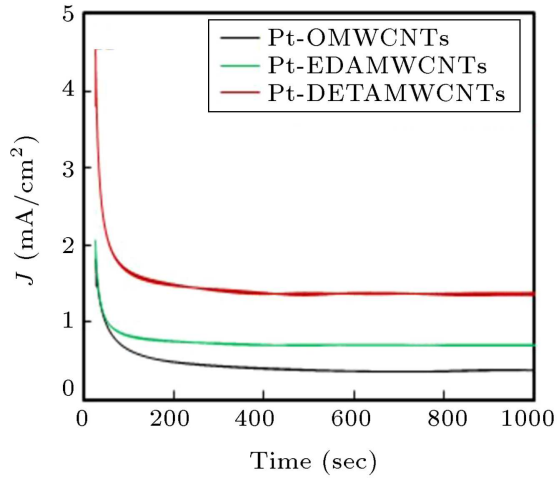

(a)

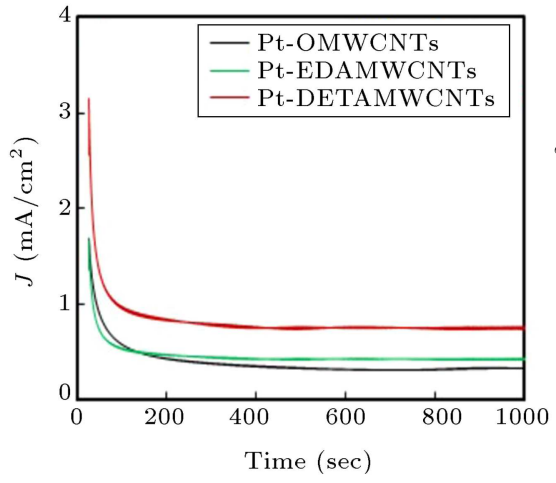

(b)

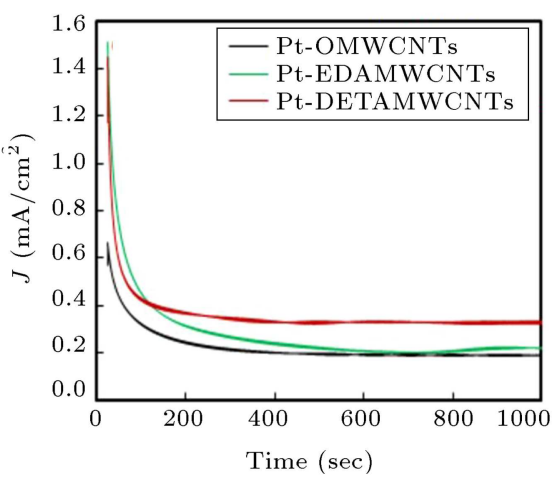

(c)

Figure 11. Chronoamperometry plots of the electrocatalysts at various applied potentials: (a) $0.75 \mathrm{~V}$, (b) $0.65 \mathrm{~V}$, and (c) $0.55 \mathrm{~V}$ versus $\mathrm{Ag} / \mathrm{AgCl}$ in oxygen-saturated $0.5 \mathrm{M} \mathrm{H}_{2} \mathrm{SO}_{4}$ at $25^{\circ} \mathrm{C}$ with the scan rate of $5 \mathrm{mV} / \mathrm{s}$.

formation of arc curves indicates that the charge transfer resistance is the dominated resistance over electrolyte resistance owing to initiation of the Nyquist curves from the origin [70]. Thus, it can be observed that the amount of charge transfer resistance or mass transport limitation is increased by increasing the diameter of the Nyquist arc curves. As can be seen, the resistance of the electrocatalysts is decreased by attaching the amine functional groups on the surface of carbon nanotubes. The amounts of $R_{s}$ and $R_{c t}$ are summarized in Table 3. On the other hand, the low amount of $R_{c t}$ verifies that the electrochemical reduction of oxygen is extremely fast; hence, the amount of $R_{c t}$ is negligible as compared to Warburg impedance. As represented by the Nyquist curves, the mass transfer limitation and Warburg impedance for Pt-DETAMWCNTs and Pt-EDAMWCNTs are less than that of Pt-OMWCNTs due to the high electron conductivity of the nitrogen atoms in amine functional groups. Furthermore, the mass transfer limitation has decreased by increasing the number of nitrogen atoms in the case of Pt-DETAMWCNTs. Therefore, the smaller slope of Nyquist curves implies that the number of transferred electrons increases by amine functionalization of carbon nanotubes, facilitating the oxygen reduction through enhancing the accessibility of Pt nanoparticles for oxygen molecules.

\subsubsection{Chronoamperometry (CA)}

In addition to the above-mentioned electrochemical techniques, chronoamperometry was applied to further evaluate the stability and catalytic activity of the electrocatalysts. Figure 11 shows chronoamperometry plots of Pt-OMWNCTs, Pt-EDAMWCNTs, and PtDETAMWCNTs at three different applied potentials. According to Figure 11, of all the applied potentials, Pt-DETAMWCNTs exhibit the most stable electro catalytic behavior due to the highest steady current density among the three electrocatalysts. Moreover, this behavior is confirmed by chronoamperometry curves of Pt-EDAMWCNTs as compared with PtOMWCNTs, enjoying the minimum current density and stability at all the applied potentials. The chronoamperometry results are consistent with all of the previous electrochemical observations. As a result, the role of amine functional groups is again indicative of the improvement of the catalytic performance of $\mathrm{Pt}$ nanoparticles.

\section{Conclusion}

The effect of amine functional groups on the reduction of oxygen at the cathodic electrode of proton exchange membrane fuel cell was investigated by functionalization of multi-wall carbon nanotubes. In addition, platinum nanoparticles were dispersed on the amine functionalized and oxidized carbon nanotubes for further evaluation of the role of amine functionalization. Electrochemical and physicochemical characterizations of Pt-OMWCNTs, Pt-EDAMWCNTs, and Pt-DETAMWCNTs demonstrate that the presence of amine functional groups on the surface of carbon nanotubes not only improves the nucleation, growth, and the dispersion of $\mathrm{Pt}$ nanoparticles, but also enhances 
the reduction of oxygen molecules. It was found that the quantity of nitrogen atoms played an important role in electrochemical reduction of oxygen. XPS and TEM results revealed that DETAMWCNTs better improved the catalytic activity of $\mathrm{Pt}$ nanoparticles due to the number of attached amine groups and higher dispersion of platinum nanoparticles as compared to EDAMWCNTs. Cyclic and linear sweep voltammetry showed that EASA, onset potential, and number of electron transfer were increased by amine functionalization of carbon nanotubes. Furthermore, EIS and CA confirmed the role of amine functional groups by decreasing the mass transfer limitation and higher stability. Overall, nitrogen atoms in the form of amine functional groups facilitate the accessibility of $\mathrm{Pt}$ nanoparticles for ORR, leading to the decrease of Pt loading while keeping 4electron pathway reduction of oxygen.

\section{Acknowledgment}

The authors would like to acknowledge the financial support of this research by University of Tehran.

\section{References}

1. Andújar, J., and Segura, F. "Fuel cells: History and updating. A walk along two centuries", Renew Sust Energ Rev, 13(9), pp. 2309-2322 (2009).

2. Costa, R. and Camacho, J. "The dynamic and steady state behavior of a PEM fuel cell as an electric energy source", J Power Sources, 161(2), pp. 11761182 (2006).

3. Girishkumar, G., McCloskey, B., Luntz, A., Swanson, S., and Wilcke, W. "Lithium- air battery: promise and challenges", J of Phys Chem Lett, 1(14), pp. 2193-2203 (2010).

4. Hassani, S.S., Ganjali, M., Samiee, L., Rashidi, A., Tasharrofi, S., Yadegari, A., Shoghi, F., and Martel, R. "Comparative study of various types of metal-free N and $\mathrm{S}$ co-doped porous graphene for high performance oxygen reduction reaction in alkaline solution", $J$ Nanosci and Nanotechno, 18(7), pp. 4565-4579 (2018).

5. Würfel, P. "Solar energy conversion with hot electrons from impact ionisation", SOL ENERG MAT SOL C, 46(1), pp. 43-52 (1997).

6. Zhang, L.L. and Zhao, X. "Carbon-based materials as supercapacitor electrodes", Chem Soc Rev, 38(9), pp. 2520-2531 (2009).

7. Shayeh, J.S., Ehsani, A., Naeemy, A., Shiri, H.M., Fatemi, F., Yadegari, A., and Omidi, M. "Electrosynthesis and characterization of poly aniline/garnet nanoparticles for high-performance electrochemical capacitors", Ionics, 24(2), pp. 505-511 (2018).

8. Tajik, S., Dubal, D.P., Gomez-Romero, P., Yadegari, A., Rashidi, A., Nasernejad, B., and Asiri, A.M. "Nanostructured mixed transition metal oxides for high performance asymmetric supercapacitors: Facile synthetic strategy", Int J Hydrogen Energ, 42(17), pp. 12384-12395 (2017).

9. Mustain, W.E. and Prakash, J. "Kinetics and mechanism for the oxygen reduction reaction on polycrystalline cobalt-palladium electrocatalysts in acid media", J Power Sources, 170(1), pp. 28-37 (2007).

10. Wang, C., Daimon, H., Lee, Y., Kim, J., and Sun, S. "Synthesis of monodisperse Pt nanocubes and their enhanced catalysis for oxygen reduction", J Am Chem Soc, 129(22), pp. 6974-6975 (2007).

11. Gasteiger, H.A., Kocha, S.S., Sompalli, B., and Wagner, F.T. "Activity benchmarks and requirements for $\mathrm{Pt}, \mathrm{Pt}$-alloy, and non-Pt oxygen reduction catalysts for PEMFCs", Appl Catal B: Environ, 56(1), pp. 9-35 (2005).

12. Yu, X. and Ye, S. "Recent advances in activity and durability enhancement of $\mathrm{Pt} / \mathrm{C}$ catalytic cathode in PEMFC: Part II: Degradation mechanism and durability enhancement of carbon supported platinum catalyst", J Power Sources, 172(1), pp. 145-154 (2007).

13. Yadegari, A., Samiee, L., Tasharrofi, S., Tajik, S., Rashidi, A., Shoghi, F., Rasoulianboroujeni, M., Tahriri, M., Rowley-Neale, S.J., and Banks, C.E., "Nitrogen doped nanoporous graphene: an efficient metal-free electrocatalyst for the oxygen reduction reaction", $R S C A d v, 7(87)$, pp. 55555-55566 (2017).

14. Kannan, R., Kakade, B.A., and Pillai, V.K. "Polymer electrolyte fuel cells using nafion-based composite membranes with functionalized carbon nanotubes", Angew Chem Int Edit, 47(14), pp. 2653-2656 (2008).

15. Tzitzios, V., Georgakilas, V., Oikonomou, E., Karakassides, M., and Petridis, D. "Synthesis and characterization of carbon nanotube/metal nanoparticle composites well dispersed in organic media", Carbon, 44(5), pp. 848-853 (2006).

16. Blackburn, J.L., Barnes, T.M., Beard, M.C., Kim, Y.H., Tenent, R.C., McDonald, T.J., To, B., Coutts, T.J., and J. Heben, M. "Transparent conductive singlewalled carbon nanotube networks with precisely tunable ratios of semiconducting and metallic nanotubes", Acs Nano, 2(6), pp. 1266-1274 (2008).

17. Georgakilas, V., Gournis, D., Tzitzios, V., Pasquato, L., Guldi, D.M., and Prato, M. "Decorating carbon nanotubes with metal or semiconductor nanoparticles", J Mat Chem, 17(26), pp. 2679-2694 (2007).

18. Maass, S., Finsterwalder, F., Frank, G., Hartmann, R., and Merten, C. "Carbon support oxidation in PEM fuel cell cathodes", J Power Sources, 176(2), pp. 444451 (2008).

19. Alexeyeva, N. and Tammeveski, K. "Electrochemical reduction of oxygen on multiwalled carbon nanotube modified glassy carbon electrodes in acid media", Electrochem Solid State Lett, 10(5), pp. F18-F21 (2007).

20. Alexeyeva, N., Tammeveski, K., Lopez-Cudero, A., Solla-Gullón, J., and Feliu, J. "Electroreduction of 
oxygen on Pt nanoparticle/carbon nanotube nanocomposites in acid and alkaline solutions", Electrochim Acta, 55(3), pp. 794-803 (2010).

21. Jukk, K., Kozlova, J., Ritslaid, P., Sammelselg, V., Alexeyeva, N., and Tammeveski, K. "Sputterdeposited Pt nanoparticle/multi-walled carbon nanotube composite catalyst for oxygen reduction reaction", J Electroanal Chem, 708(1), pp. 31-38 (2013).

22. Kaempgen, M. and Roth, S. "Ultra microelectrodes from MWCNT bundles", Synthetic Met, 152(1), pp. 353-356 (2005).

23. Chen, Y., Wang, J., Liu, H., Li, R., Sun, X., Ye, S., and Knights, S. "Enhanced stability of Pt electrocatalysts by nitrogen doping in CNTs for PEM fuel cells", Electrochem Commun, 11(10), pp. 2071-2076 (2009).

24. Li, H., Liu, H., Jong, Z., Qu, W., Geng, D., Sun, X., and Wang, H. "Nitrogen-doped carbon nanotubes with high activity for oxygen reduction in alkaline media", Int J Hydrogen Rnerg, 36(3), pp. 2258-2265 (2011).

25. McClure, J.P., Thornton, J.D., Jiang, R., Chu, D., Cuomo, J.J., and Fedkiw, P.S. "Oxygen reduction on metal-free nitrogen-doped carbon nanowall electrodes", J Electrochem Soc, 159(11), pp. F733-F742 (2012).

26. Su, F., Tian, Z., Poh, C. K., Wang, Z., Lim, S.H., Liu, Z., and Lin, J. "Pt nanoparticles supported on nitrogen-doped porous carbon nanospheres as an electrocatalyst for fuel cells", Chem of Mater, 22(3), pp. 832-839 (2009).

27. Yu, D., Zhang, Q., and Dai, L. "Highly efficient metalfree growth of nitrogen-doped single-walled carbon nanotubes on plasma-etched substrates for oxygen reduction", J Am Chem Soc, 132(43), pp. 15127-15129 (2010).

28. Zhao, A., Masa, J., Schuhmann, W., and Xia, W. "Activation and stabilization of nitrogen-doped carbon nanotubes as electrocatalysts in the oxygen reduction reaction at strongly alkaline conditions", J Phys Chem C, 117 (46), pp. 24283-24291 (2013).

29. Ebbesen, T.W., Hiura, H., Bisher, M.E., Treacy, M.M., Shreeve-Keyer, J. L., and Haushalter, R.C. "Decoration of carbon nanotubes", Adv Mater, 8(2), pp. 155-157 (1996).

30. Liu, Z., Lin, X., Lee, J.Y., Zhang, W., Han, M., and Gan, L.M. "Preparation and characterization of platinum-based electrocatalysts on multiwalled carbon nanotubes for proton exchange membrane fuel cells", Langmuir, 18(10), pp. 4054-4060 (2002).

31. Yang, C., Hu, X., Wang, D., Dai, C., Zhang, L., Jin, H., and Agathopoulos, S. "Ultrasonically treated multi-walled carbon nanotubes (MWCNTs) as PtRu catalyst supports for methanol electrooxidation", $J$ of Power Sources, 160(1), pp. 187-193 (2006).

32. Dudin, P.V., Unwin, P.R., and Macpherson, J.V. "Electrochemical nucleation and growth of gold nanoparticles on single-walled carbon nanotubes: New mechanistic insights", J Phys Chem C, 114(31), pp. 13241-13248 (2010).
33. Rashidi, A., Akbarnejad, M., Khodadadi, A., Mortazavi, Y., and Ahmadpourd, A. "Single-wall carbon nanotubes synthesized using organic additives to CoMo catalysts supported on nanoporous MgO", Nanotechnology, 18(31), p. 315605 (2007).

34. Chetty, R., Kundu, S., Xia, W., Bron, M., Schuhmann, W., Chirila, V., Brandl, W., Reinecke, T., and Muhler, M. "PtRu nanoparticles supported on nitrogen-doped multiwalled carbon nanotubes as catalyst for methanol electrooxidation", Electrochim Acta, 54(17), pp. 42084215 (2009).

35. Fu, X., Yu, H., Peng, F., Wang, H., and Qian, Y. "Facile preparation of $\mathrm{RuO} 2 / \mathrm{CNT}$ catalyst by a homogenous oxidation precipitation method and its catalytic performance", Appl Catal A: Gen, 321(2), pp. 190-197 (2007).

36. Liu, J., Wang, H., Wu, C., Zhao, Q., Wang, X., and Yi, $\mathrm{L}$. "Preparation and characterization of nanoporous carbon-supported platinum as anode electrocatalyst for direct borohydride fuel cell", Int J Hydrogen Energ, 39(12), pp. 6729-6736 (2014).

37. Varela, F.R. and Savadogo, O. "Catalytic activity of carbon-supported electrocatalysts for direct ethanol fuel cell applications", J Electrochem Soc, 155(6), pp. B618-B624 (2008).

38. Pozio, A., De Francesco, M., Cemmi, A., Cardellini, F., and Giorgi, L. "Comparison of high surface Pt/C catalysts by cyclic voltammetry", J Power Sources, 105(1), pp. 13-19 (2002).

39. Lambert, J.-F. and Che, M. "The molecular approach to supported catalysts synthesis: state of the art and future challenges", J MolCatal A: Chem, 162(1), pp. 5-18 (2000).

40. Dubau, L., Hahn, F., Coutanceau, C., Léger, J.-M., and Lamy, C. "On the structure effects of bimetallic PtRu electrocatalysts towards methanol oxidation", $J$ Electroanal Chem, 554(2), pp. 407-415 (2003).

41. Gao, W., Alemany, L.B., Ci, L., and Ajayan, P.M. "New insights into the structure and reduction of graphite oxide", Nature Chem, 1(5), pp. 403-408 (2009).

42. Omidi, M., Yadegari, A., and Tayebi, L. "Wound dressing application of $\mathrm{pH}-$ sensitive carbon dots/chitosan hydrogel", RSC Adv, 7(18), pp. 10638-10649 (2017).

43. Huang, M., Xu, X., Yang, H., and Liu, S. "Electrochemically-driven and dynamic enhancement of drug metabolism via cytochrome P450 microsomes on colloidal gold/graphene nanocomposites", RSC $A d v, \mathbf{2}$ (33), pp. 12844-12850 (2012).

44. Liu, K., Zhang, J., Yang, G., Wang, C., and Zhu, J.-J. "Direct electrochemistry and electrocatalysis of hemoglobin based on poly (diallyldimethylammonium chloride) functionalized graphene sheets/room temperature ionic liquid composite film", ElectrochemCommun, 12(3), pp. 402-405 (2010). 
45. Wang, S., Yu, D., Dai, L., Chang, D.W., and Baek, J.B. "Polyelectrolyte-functionalized graphene as metalfree electrocatalysts for oxygen reduction", ACS Nano, 5(8), pp. 6202-6209 (2011).

46. Mawhinney, D.B., Naumenko, V., Kuznetsova, A., Yates, J.T., Liu, J., and Smalley, R. "Infrared spectral evidence for the etching of carbon nanotubes: ozone oxidation at $298 \mathrm{~K}$ ", J Am Chem Soc, 122(10), pp. 2383-2384 (2000).

47. Ababou-Girard, S., Sabbah, H., Fabre, B., Zellama, K., Solal, F., and Godet, C. "Covalent grafting of organic layers on sputtered amorphous carbon: Surface preparation and coverage density", J Phys Chem C, 111(7), pp. 3099-3108 (2007).

48. Jiang, W., Nadeau, G., Zaghib, K., and Kinoshita, K. "Thermal analysis of the oxidation of natural graphiteeffect of particle size", Thermochim Acta, 351(1-2), pp. 85-93 (2000).

49. Kim, S.Y., Lee, J.C., Na, W., Park, J., Seo, K., and Kim, B. "N-doped double-walled carbon nanotubes synthesized by chemical vapor deposition", Chem Phys Lett, 413(4-6), pp. 300-305 (2005).

50. Ago, H., Kugler, T., Cacialli, F., Salaneck, W.R., Shaffer, M.S., Windle, A.H., and Friend, R.H. "Work functions and surface functional groups of multiwall carbon nanotubes", J Phys Chem B, 103(38), pp. 8116-8121 (1999).

51. Baker, S.E., Cai, W., Lasseter, T.L., Weidkamp, K.P., and Hamers, R.J. "Covalently bonded adducts of deoxyribonucleic acid (DNA) oligonucleotides with single-wall carbon nanotubes: synthesis and hybridization", Nano Lett, 2(12), pp. 1413-1417 (2002).

52. Nath, M., Satishkumar, B., Govindaraj, A., Vinod, C., and Rao, C.N.R. "Production of bundles of aligned carbon and carbon-nitrogen nanotubes by the pyrolysis of precursors on silica-supported iron and cobalt catalysts", Chem Phys Lett, 322(5), pp. 333-340 (2000).

53. Lin, Y., Rao, A.M., Sadanadan, B., Kenik, E.A., and Sun, Y.-P. "Functionalizing multiple-walled carbon nanotubes with aminopolymers", Journal Phys Chem $B, \mathbf{1 0 6}(6)$, pp. 1294-1298 (2002).

54. Moulder, J., Stickle, W., Sobol, P., and Bomben, K., Handbook of X-Ray Photoelectron Spectroscopy, pp. 565-575, Perkin-Elmer Corporation, USA (1992).

55. Marković, N. and Ross, P.N. "Surface science studies of model fuel cell electrocatalysts", Surf Sci Rep, 45(4), pp. 117-229 (2002).

56. Ghorbani-Vaghei, R., Hemmati, S., Hashemi, M., and Veisi, H. "Diethylenetriamine-functionalized singlewalled carbon nanotubes (SWCNTs) to immobilization palladium as a novel recyclable heterogeneous nanocatalyst for the Suzuki-Miyaura coupling reaction in aqueous media", CR Chim, 18(6), pp. 636-643 (2015).

57. Mugadza, T. and Nyokong, T. "Covalent linking of ethylene amine functionalized single-walled carbon nanotubes to cobalt (II) tetracarboxylphthalocyanines for use in electrocatalysis", Synthetic Met, 160(19), pp. 2089-2098 (2010).

58. Koenigsmann, C., Zhou, W.-P., Adzic, R.R., Sutter, E., and Wong, S.S. "Size-dependent enhancement of electrocatalytic performance in relatively defect-free, processed ultrathin platinum nanowires", Nano Lett, 10(8), pp. 2806-2811 (2010).

59. Subhramannia, M. and Pillai, V.K. "Shape-dependent electrocatalytic activity of platinum nanostructures", $J$ Mat Chem, 18(48), pp. 5858-5870 (2008).

60. Yang, T., Ling, H., Lamonier, J.-F., Jaroniec, M., Huang, J., Monteiro, M.J., and Liu, J. "A synthetic strategy for carbon nanospheres impregnated with highly monodispersed metal nanoparticles", NPG Asia Mate, 8(2), p. e240 (2016).

61. Mayrhofer, K., Strmcnik, D., Blizanac, B.B., Stamenkovic, V., Arenz, M., and Markovic, N.M. "Measurement of oxygen reduction activities via the rotating disc electrode method: From Pt model surfaces to carbon-supported high surface area catalysts", Electrochim Acta, 53(7), pp. 3181-3188 (2008).

62. Reyes-Rodriguez, J., Godínez-Salomón, F., Leyva, M., and Solorza-Feria, O. "RRDE study on Co Pt/C coreshell nanocatalysts for the oxygen reduction reaction", Int $J$ of Hydrogen Energ, 38(28), pp. 12634-12639 (2013).

63. Mayrhofer, K., Strmcnik, D., Blizanac, B., Stamenkovic, V., Arenz, M., and Markovic, N. "Measurement of oxygen reduction activities via the rotating disc electrode method: From Pt model surfaces to carbon-supported high surface area catalysts", Electrochim Acta, 53(7), pp. 3181-3188 (2008).

64. Mayrhofer, K., Blizanac, B., Arenz, M., Stamenkovic, V., Ross, P., and Markovic, N. "The impact of geometric and surface electronic properties of Pt-catalysts on the particle size effect in electrocatalysis", $J$ Phys Chem B, 109(30), pp. 14433-14440 (2005).

65. Ocampo, A., Castellanos, R., and Sebastian, P. "Kinetic study of the oxygen reduction reaction on $\mathrm{Ru} \sim \mathrm{y}$ $(\mathrm{CO}) \sim \mathrm{n}$ in acid medium with different concentrations of methanol", J of New Mat for Elect Sys, 5(3), pp. 163-168 (2002).

66. Cheng, F., Su, Y., Liang, J., Tao, Z., and Chen, J. " $\mathrm{MnO}_{2}$-based nanostructures as catalysts for electrochemical oxygen reduction in alkaline media", Chem Mater, 22(3), pp. 898-905 (2009).

67. Xie, Z. and Holdcroft, S. "Polarization-dependent mass transport parameters for orr in perfluorosulfonic acid ionomer membranes: an EIS study using microelectrodes", J of Electroanal Chem, 568(3), pp. 247-260 (2004).

68. Du, C., Zhao, T., and Yang, W. "Effect of methanol crossover on the cathode behavior of a DMFC: A halfcell investigation", Electrochim Acta, 52(16), pp. 52665271 (2007). 
69. Piela, P., Fields, R., and Zelenay, P. "Electrochemical impedance spectroscopy for direct methanol fuel cell diagnostics", J of the Electrochem Soc, 153(10), pp. A1902-A1913 (2006).

70. Morales-Acosta, D., De La Fuente, D.L., Arriaga, L., Gutiérrez, G.V., and Varela, F.R. "Electrochemical investigation of Pt-Co/MWCNT as an alcohol-tolerant ORR catalyst for direct oxidation fuel cells", Int. Electroche Soc, 6(1), p. 1835 (2011).

\section{Biographies}

Amir Yadegari received his MSc in Chemical Engineering from University of Tehran in 2013. He currently works as a Research Associate at Marquette University. His main area of research is related to the preparation of nanomaterials for biomedical engineering and energy storage, especifically the applications of carbon nanostructures including carbon dots, carbon nanotubes, graphene and its derivatives.

Amiddedin Nouralishahi received his MSc and $\mathrm{PhD}$ in Chemical Enginering from Tarbiat Moadares University and University of Tehran, Iran, respectively. He is an Assistant Professor at Caspian Faculty of Engineering, College of Engineering, University of Tehran. His main research interests include preparation and characterization of carbon nanomaterials for energy conversion and storage, specifically in electrochemical devices.

Yadollah Mortazavi received BSc degree in Chemical
Engineering from University of Shiraz, Shiraz, Iran, and $\mathrm{MSc}$ and $\mathrm{PhD}$ degrees in Chemical Engineering from the University of Waterloo, Waterloo, Ontario, Canada. He joined University of Tehran in 1995 and is currently the Chairman of Nanotechnology Department of College of Engineering, University of Tehran, Tehran, Iran. His research interests include catalysis and reaction engineering, especially in CI chemistry, air pollution control, chemical gas sensors, and nanostructured materials.

Abbas Ali Khodadadi received his MSc in Chemical Engineering from University of Tehran in 1986 and his $\mathrm{PhD}$ in Catalysis and Reaction Engineering from University of Waterloo, Canada in 1994. His research interests include synthesis of nanostructured materials, including metals (oxides), carbon nanotubes, graphene, etc., through various methods and their applications in nano/bio/photo/plasma-catalytic reactions, gas/biosensing, nano filters and membranes for natural gas and petroleum conversions and air pollution control.

Alimorad Rashidi received his $\mathrm{MSc}$ and $\mathrm{PhD}$ in Chemical Engineering from University of Tehran. He is currently a Professor at Research Institute of Petroleum Industry (RIPI). His main research interests include various applications of nanomaterials, mainly carbon nanostructures such as CNT, CNF, and graphene. He also works on preparation, characterization, and evaluation of nanomaterials in chemical engineering. 